The 49th Annual Conference of the International Association of School Librarianship

The 24th International Forum on Research on School Librarianship

July $12-16,2021$

Elizabeth A. Burns

Old Dominion University

eburns@odu.edu

\title{
Weaving Diversity into LIS Instruction: Equity Behaviors to Create the Tapestry of Inclusive Library Practice
}

\begin{abstract}
Libraries should be inclusive spaces for all patrons. It is imperative today's librarians are equipped to infuse diversity, equity, and inclusion (DEI) theory with best practice when establishing policy and procedure. Library preparation programs must prepare the next generation of librarians to meet the needs of a diverse population, however, there are no established protocols in LIS education for training pre-service librarians in DEI. This exploratory study examines how one class used a culturally responsive pedagogy (CRP) framework to study issues of diversity, equity, and inclusion in library services. Findings suggest LIS students who interrogate their own bias and integrate thoughtful equity behaviors adopt greater empathy and DEI strategies
\end{abstract}

Keywords: Culturally Relevant Pedagogy, DEI, Library Education, Social Justice

\section{Introduction}

The American Library Association's Library Bill of Rights (ALA, 1996) ensures the "right to use a library regardless of origin, age, background, or views." Libraries, as public spaces, serve a diverse population of users. The 2010 United States Census Bureau report showed that twenty-two percent of the United States population was people of color (USCB, 2018). This percentage is expected to increase with the published 2020 census. Librarians must effectively attend to the dynamic needs of all patrons. Therefore, it is imperative today's librarians are equipped with skills to critically consider the library environment, staff, user services, collections, and programming to best assist all patrons, especially those who may represent underserved or culturally disenfranchised populations.

Ideals of social justice, along with respect for diversity, are foundational to the core values of the library profession (ALA, 2010; ALA, 2019). However, with no established model for integrating these ideals into LIS education it is unclear how pre-service librarians are trained to meet the needs of a racially diverse set of users. In the past several decades, social justice education has been emphasized across disciplines (Goodwin, 1997). Those of the dominant race have been challenged (DiAngelo, 2018) to critically explore their own identity and to directly address race and difficult conversations of racial disparity. This challenge presents an educational need to 
address issues of equity, racial diversity, and cultural literacy in library pre- and in-service library training to develop the awareness and empathy required to provide user services to the increasingly diverse set of patrons most librarians will serve in their information setting.

Early attempts at equity and racial education have lacked depth. Goodwin (1997) chastised the education community for a narrow attempt to build cultural awareness by simply infusing multicultural or racial awareness into an already comprehensive education curriculum with a one-shot course or learning session. Since that time, efforts have been made within LIS programs to thread issues of diversity, equity and inclusion work into coursework and programs more holistically, largely in response to meeting accreditation standards where language has been included to ensure attention to diverse learning styles, literature, and pedagogy (CAEP, 2019). The LIS program explored in this study includes diversity, equity, and inclusion (DEI) as a central objective underpinning the program while also offering a stand-alone course Culturally Responsive Librarianship to further deepen and critically interrogate understanding of diversity, to include racial and ethnic factors, in key areas of librarianship.

\section{Statement of Research Problem}

This exploratory study, framed using an action research (AR) model, (Creswell, 2012) asked emerging librarians to reflectively interrogate their understanding of racial diversity as it impacts the key areas of library services: collections, programing, facilities, as well as the extent to which policy guiding these areas impacts diverse users using a developed conceptual framework centered on the ideals of cultural competence that derive from the work in education on culturally relevant pedagogy (Landson-Billings, 1995a). This understanding is situated in the context of how a LIS program prepares new information professionals to critically explore racial issues and reflect on library practices. Emerging librarians focused on race and their own shifts in understanding about how patron racial diversity may shape considerations of library use and policy. These ideas were explored as they engaged with course materials. This study is guided by the following question:

In what way does use of a cultural competency framework in preservice coursework impact emerging librarians' perspective on how to meet the needs of racially diverse populations?

\section{Review of Literature}

\section{Social Justice as Theoretical Framework}

Successful diversity, equity, and inclusion (DEI) work begins with and progresses beyond acknowledging personal bias to also identify an individual's role in systemic functions and to challenge assumptions about ourselves and others (Drago-Severson, 2016). This often requires individuals to identify and come to terms with unrecognized advantages or privilege. As an approach to exploring diversity, equity, and inclusion within this research, social justice theory guided inquiry as a path to greater understanding. 
Adams, Bell, \& Griffins' (2007) definition of social justice includes a vision of a society in which the distribution of resources is equitable, where all members are physically and psychologically safe and secure. Aligned to the tenets of the Library Bill of Rights (ALA, 1996) this definition underpins and frames the work of LIS instruction. The mission of the library supports social justice, a doctrine against social oppression due to racism, ageism, classism, ableism, and heterosexism, etc. in society.

\section{Culturally Relevant Pedagogy}

Growing out of social justice education in the university setting, sometimes referred to as "teaching for social justice," is the contextual concept of culturally relevant pedagogy (Ladson-Billings, 1995a). Culturally Relevant Pedagogy specifically explores race and culture when framing new understanding in an educational context (Cochran-Smith, 2010; Darling-Hammond, 2010). For this purpose, a culturally centered framework is an appropriate path for instruction in a variety of educational settings, (Kugler \& West-Burns, 2015; Ladson-Billings, 1995a) to include LIS programs.

Culturally relevant teaching uses cultural knowledge, prior experiences, and the performance styles of diverse students to make learning appropriate and effective; it considers the strengths of a diverse group of students to engage learners (Ladson-Billings, 1995a, 1995b). The goal of culturally relevant teaching is to create a learning environment effective for all students, no matter their ethnic, cultural, economic, or linguistic backgrounds. Ladson-Billings (1995a) reminds us that the benefits of including these practices are a more positive environment and greater engagement of the learner and the instructor, particularly when emphasis is placed on knowledge and consideration of the learners.

Using a framework grounded in these theories ensures that diverse needs are considered regardless of any potential bias the teacher may hold. Culturally responsive teachers ensure the culture of the classroom is inclusive of all students (Ladson-Billings, 1995a, 1995b; Villegas \& Lucas, 2002). These concepts were developed and used throughout the study for context, development, and framing.

\section{Study Design}

This study used an Action Research (AR) model (Mills, 2014) to frame an exploratory investigation of the beliefs of emerging librarians through course discourse.

\section{Action Research}

Action Research (AR) seeks to identify an area of focus or concern, collect data, analyze, and interpret the data to suggest solutions to the identified problem, and then develop an action plan (Mills, 2014). The AR model provided an opportunity to address the focus of race and diversity 
instruction as a problem to explore. Student interaction and engagement using a developed framework provided data and established a plan for future work (Mills, 2014). The advantages to using AR in this study include the opportunity to implement a new framework and reflect on the impact and effectiveness of the developed stages of the cultural competence framework for the preparatory course.

\section{Researcher as Participant}

Consistent with action research, I examined my own growth and understanding in cultural awareness. As a white scholar, educator, and researcher, I interpreted my own implicit and explicit bias in the creation of the course content and the project and bracketed these as a basis for future understanding (Hayes \& Singh, 2012). I developed a cultural pedagogy framework and planned the instructional components of the preparation course. I communicated the course requirements to the preservice candidates.

Additional planning was done on my part to provide instruction, instructional materials, and guide preservice candidate learning through both synchronous and asynchronous instruction. This instruction grounded candidate understanding of culturally relevant pedagogy (Ladson-Billings, 1995a). This could at once be considered planning and action in the AR model. Later, I reflected on the course design, effectiveness in meeting the framework and overall learning of the pre-service candidates. The pre-service candidates did not have a role in planning the research model. They were participants in the research and worked through the stages of the framework as they completed the course requirements. Throughout the stages of the framework, the candidates reflected on the impact the course content was having on their beliefs and understandings about race.

\section{Pre-Service Participants}

Data were collected from one class of emerging library professionals enrolled in a course titled Culturally Responsive Librarianship. Eighteen participants were enrolled in the course, offered as an elective for the LIS program. Students were at various points in their program of study, with some enrolled in their first semester and others taking the course as one of their final courses prior to graduation. All participants were enrolled at the graduate level and planned to pursue a career in a library information setting. Further participant demographics show all students were white females and lived in a variety of geographic settings within one mid-Atlantic state representing rural, suburban, and urban environments.

\section{Data and Analysis}

\section{A Cultural Competence Framework Applied to Library Practice}

A framework was developed to guide the curriculum and work of the pre-service library participants. The framework included four stages, introduced progressively, though the pre-service candidates engaged with the stages in an iterative cycle, able to revisit and reflect on 
their journey as was individually appropriate. Each stage was clearly articulated through the course materials. The following describes each of the framework stages:

Stage One-Develop a Sociocultural Awareness: includes self-reflection to identify any implicit or explicit bias.

Stage Two- Develop an Interpersonal Awareness: includes building an understanding of and empathy for others. This stage requires engaging in difficult conversations about personal bias as well as confronting the treatment of others in society.

Stage Three-Accept Responsibility for Change: includes not only ownership of the need to improve, but development of a personal plan for improvement with identified action steps and measures of accountability and progress.

Stage Four- Lend a Voice or Actions: includes establishing a vision and goals to act as a change agent within society; to be a voice within the library community for equity and inclusion.

\section{Data Collection}

Three data sources were collected and analyzed for each participant. Data therefore included: an initial reflection on personal bias and scored assessment inventories, a reflection on race situated within a literature discussion using the texts Evicted: Poverty and Profit in an American City by Mathew Desmond (2016) and Citizen: an American Lyric by Claudia Rankine (2014), and a final reflection on personal growth. Each participant engaged with the same course materials and course readings. Within assignments, diversity, equity, and inclusion were discussed broadly and included a scope wider than race. However, analysis and findings for this study focus specifically on those discussions of race in participant responses.

\section{Data Analysis}

Based on the goals of the research question, a constructivist grounded theory approach was used for data analysis (Charmaz, 2006). Using the descriptive, inductive approach of constructivist, grounded theory allowed for examination of individual responses. Using statements as units of analysis, data were coded to identify emergent categories. A focused code log was created to identify underlying themes in participant responses. (Charmaz, 2006). Themes that captured the stages of the developed CRP framework served as the initial set of structural codes: identity, bias, empathy, acknowledgement, color blindness, acceptance, and action. The researcher detailed emerging patterns within identified categories and reviewed a subset of the data with a co-researcher to ensure validity and reliability of the codes. Participant reflections were then aligned to the developed four stages of the pedagogy framework. Discussion of findings below are organized by the AR model, to demonstrate the impact this framework had with this group of candidates and to suggest a plan going forward. Participant quotations help to illustrate these findings. 


\section{Findings}

Data samples from each participant were examined to identify patterns of thought in their beliefs and perceptions on diversity, equity, and inclusion practices in relation to library practice. From this analysis, the following four broad themes were captured: identifying growth in discomfort, building cultural awareness, shifting toward racial empathy, envisioning a culturally responsive library. Each theme is discussed in depth with participant quotes and description to provide thick description and meaning in context. The results of this exploratory study are presented through the action research stages.

\section{Framing the Problem}

I began the study by identifying a need for exploration (Creswell, 2012). Stage one of AR begins with the identification of a problem of practice. This identification led to a plan for change. In this study, the plan resulted in a developed cultural competence framework that formed the coursework and explored participant progress.

As an introductory activity of the course, students were asked to assess and identify their own explicit and implicit bias. Students then reflected on their findings. This early assignment was challenging as students built their own understanding of cultural awareness and reflected on their personal beliefs. Though participants identified with many roles and positions within society, they remained safe within their identity classification and did not disrupt the language of civility (DiAngelo, 2018) or enter conversations about race. Participants identified by gender, profession, sexual orientation, and family role, but no one stated their race in opening identity exercises.

As the course continued, deeper issues of bias were probed. Many participants expressed disbelief or discomfort with their findings. They even avoided mention of words that identified race, when possible, as if perhaps making the outcome sound less damaging. Carol and Jess demonstrate this, "What I was not expecting was that I might have bias against people of deeper hued skin. It was disconcerting to find that out about myself" (Carol) and "The most uncomfortable moment for me was when I found I favored European Americans as opposed to African Americans. I was very upset about this" (Jess). Hope struggled with language and words used to refer to race in general,

I am white. Just typing that makes me uncomfortable. It makes me anxious to use adjectives to describe individuals. I don't know how to properly acknowledge someone's "otherness" without treading too far -so I just avoid it all costs.

Other participants went so far as to disagree with the result of a bias inventory as it pertained to race, though they did not disagree with the validity of the assessments as a whole, offering up a rationale for why the test may have assigned the bias:

I disagree with the strongly preferring lighter skinned people to darker skinned people. I do not disagree with the sexual orientation assessment. I do know that 
preferring the company of lighter skinned people is partially due to not having darker skinned people around to socialize with in my life. (Kelly)

Perhaps because it was an early assignment and used as an exercise in self-exploration, some students equated having a racial bias to not being a good person. "I think of myself as a good person, yet, I was faced with the fact that I am consciously and unconsciously making choices and decisions that may, in fact, be hurtful to others." (Holly)

Other participants did not deny personal bias, but instead simply put forward a rationale for any disclosed racial bias. These accepted racial biases then explored a clear line within their past or within established relationships and community that could be the potential cause for such a set of beliefs. Sharon exemplifies this here:

It is suggested I have a slight automatic preference for White people over Black people. I grew up in what was a small town in California. It was not a very diverse community. We did have a couple of families of farmworkers from Mexico that would send their children to school during the months they worked in town. We did not have any African-American students at our school until I was in sixth grade. I believe that part of my bias may be due to my lack of understanding of the culture of people of color.

A small number of students in the course were more accepting of the challenge of this reflective assessment to confront their implicit bias. They seemed to understand that identifying racial bias was an important step to working with diverse populations and that there was potential harm in not doing this initial, self-reflective work. These participants were ready to embrace the identification of racial bias, though it did not prevent discomfort within their reflection. This participant group further viewed the identification of their bias as an opportunity for personal growth. Jenni expresses this sentiment,

I am a bit uncomfortable. I am perhaps a little bit more biased than I had thought coming into this experience. I see this as a good thing though. I have learned that I have a strong automatic preference to European Americans over African Americans. I want to truly address this because I do not want to possess this preference.

This is further echoed by Mary, who suggests a path forward, "With the readings and the realizations that I have made about myself I realize that the first thing to change needs to be me."

\section{Implementing the Stages: Participant Growth in Action}

With identification, the initial groundwork set and action prepared, both the participants and I began the active stage of the AR model. This involved using the developed framework to progress beyond discomfort to gain empathy and form new beliefs and attitudes that can be applied to library practice. 
Engaging with course materials and readings provided participants with the perspective of what it may be like as the non-dominant race. The course materials presented information on race and racial tensions in a manner that was new or heightened the understanding of racial minorities for some participants, "After the readings in this class, especially Citizen: An American Lyric by Claudia Rankine, my understanding of what it is like to not be a part of the dominant white culture in America was developed" (Holly). The participants began to have a deeper personal understanding about the impact of race and society through the character's experiences, "I never realized how micro-aggressions really affect people but can now better understand how people feel "(Amy). As Kelly noted, some of the content provided a much-needed perspective,

The book was bone chilling in some places. It opened my eyes to what African Americans go through daily. I do not have to deal with any of this and I do not know how I would cope with these feelings daily.

In group discussions, there was clear unease with racial tensions and a general sense of being uncomfortable with the content, as well as the conversation. While the topics of both course texts proved difficult, situating race within a socio scientific discussion of poverty in the book Evicted proved easier to discuss than the nearly exclusive discussions of race and racial relationships within society that were the central theme in Citizen: An American Lyric. This was shared multiple times.

Discussing books like Evicted and Citizen can be difficult because they are books on topics that many people are uncomfortable talking about. I admit that I struggled more with Citizen than with Evicted. Evicted followed both victims and perpetrators of different races and ethnicities without heavily focusing on the effect of racial bias on their situations. (Beth)

Citizen was more emotional and focused specifically on white bias, discrimination, and aggression against blacks. It was much rawer and condemning. My group was very open and candid while discussing Evicted, but the whole atmosphere shifted when we switched to Citizen. I think we were all moved by the book's honesty and transparency, but the material was painful to address. (Marti)

The use of language: You verses We, to include the use of second person narrative to establish and highlight instances of racial bias within the book Citizen further heightened unease in the literature discussions as the participants began to feel the weight of some of the societal issues being discussed, "Black Americans are given little choice other than being the "you" to white America. This idea paired with the fact that I am part of white America was particularly difficult 
for me to come to terms with" (Holly). These discussions begin to demonstrate a shift in thinking and building of empathy toward others:

I carry implicit biases that I intellectually do not support and am trying to acknowledge so that I can move past them in both internal and external ways. Through her poetry and deliberate second person point of view, I was forced to see and experience situations and current events in ways I hadn't before; I was called out for my behaviors and biases. I had never before felt so keenly how it is to be viewed as "other." (Holly)

Systemic oppression of racial groups was discussed as participants observed this through the characters in the literature. Several participants connected with the concept of white privilege as exemplified through the readings, even if they had originally been averse to the idea that they had any sort of racial bias, such as Kelly, "I found myself feeling far more sympathetic towards the African American characters and judgmental towards the Caucasian characters, even though the characters from both races were considered poor" (Kelly) and Hope, "Many live in a world where poverty is imposed on them. This then causes the dominoes to fall - students who don't show up for school, part time employees who just disappear, the need for reimaged public housing and more."

The participants identified perseverance against societal barriers associated with African Americans they did not perceive in the white characters, which was an interesting finding:

Also, in Scott's case [Scott is white], he had a choice to ask for help. Doreen, Arleen and Vanetta [all black characters] did not have the option of turning to a family member to help them out financially or otherwise. The differences of the root causes of the reasons for poverty for these families was difficult to manage for me. For the majority of the African American families, generational poverty with no real path to exit was eye opening. (Carol)

A newfound understanding and awareness for people they may encounter in similar situations manifest for the participants.

Some of our students bounced around from school to school because their families were moving from apartment to apartment. If I'm being honest, I don't think I ever really stopped to think about the situations that caused each of those families to have to move. From now on, I will be thinking differently, and I will continue to grow my own empathy by reading more about others' experiences. (Lori)

The participants identified personal ignorance but presented an openness to learning more as they went through the course materials and engaged in open conversations and reflections. 
Having confronted their personal bias and worked to understand some of the lived experiences of those from another race, participants were able to establish a greater awareness and understanding of ideas that were once elusive to them. Participants were better able to define and personally connect to the ideas of diversity, equity, and inclusion. Sue simply stated, "This class has opened my eyes to the fact that our unconscious plays a big part in how we treat others".

Participants progressed from simply understanding terminology and concepts to an appreciation of these ideas in context,

I felt that I understood equity but perhaps, I really just understood the definition of equity. It is an intricate web of ideas and motivations. It's not easy to discuss, argue, admit insecurities or to view equity from someone who really has never known inequalities. This course allowed me to understand it internally (Sue).

For some, this meant exploring topics that were elusive or outside a participant's scope of experience.

Breaking through this I believe the hardest part of discussing the issues of the readings with my group was the fact that I lacked knowledge of many of the situations. As an educated woman who has worked in the school systems for over 15 years, I was oblivious to the racial profiling that occurs in the housing industry. I admitted in our meeting that it never occurred to me that a family was moving due to eviction and this made me feel small, especially as a teammate made the comment that she is used to this with her students. The course gives us a perspective outside of our own. Taking a walk in someone else's shoes can change your whole perspective. (Julie)

This is further explained by Beth:

I fell short on realizing the full range of what a diverse and inclusive library should look like. In thinking about diversity, I pictured people who are from lower income back-grounds, inner city, and most likely to be African American or single mothers. While this is certainly one type of people who lack representation in our libraries, it is also a fantastic example of stereotyping. This doesn't represent an entire group of people.

Participants progressed in their understanding of culture and identity in a way that prepared them to understand diversity and difference as something to acknowledge. For many, this presented as a shift from "color blind thinking" to a more inclusive means of interaction. Participants began to recognize cultural and racial diversity instead of blanketly applying a one-size-fits-all approach to their concept of library services, "I didn't think about my cultural blindness being a negative thing, but I have recently discovered that when no resources, attention, time, or teaching are devoted to understanding cultural differences everyone is denied important aspects of their 
identity" (Tammi). The shift from cultural celebrations to inclusive thinking was also key to understanding impactful diversity and equity:

Previously, I would have thought that a collection that included various cultures food, fashion, famous people, festivals, and flags, would be a strong and inclusive collection. I understand now how limiting the literature to this depiction would strengthen stereotypes and make underrepresented populations feel more isolated. A diverse collection should depict an accurate portrayal of modern life to not only benefit underrepresented populations but lead to a more empathetic and culturally competent community as a whole, one that recognizes differences as a healthy part of our world.(Sue)

\section{A Plan Forward-Reflecting on Progress and Continuing the Work}

The final step in the AR model is to reflect on the process and make plans to carry work forward. At the conclusion of the course and after implementing the culturally responsive framework, the preservice librarians were able to demonstrate insightful progress in their own personal growth. Plans for sustaining their work were expressed.

The framework fostered an opportunity for participants to experience a cultural awakening. Participants document a cultural awareness for developing a culturally responsive library, "I have developed a sense of responsibility to make sure all patrons are provided with diverse collections, resources, and programming that challenges their thinking, that promotes a counternarrative, and that keeps issues facing marginalized groups current" (Holly).

They acknowledged their personal growth and accepted the challenge of applying this toward library practices and policies to improve DEI initiatives, "I also recognize that my own personal growth has been substantial, and I confidently feel that I will have a positive impact on my future library community" (Beth).

Participants understood that DEI work must go beyond personal action. They planned initiatives beyond their individual goals to include policy decisions and systemic changes within an information setting, "I need to not only help students of color by creating library policies that foster inclusion, but also by creating opportunities for others to learn about the contributions of marginalized groups and the importance of inclusion for everyone" (Sharon).

This also transferred to a commitment to build understanding in others:

Further, a library that is truly culturally competent builds positive learning partnerships with the community it serves. ensuring access and connection for all possible users must be willing to reflect on their own cultural lenses, acknowledge and work on existing prejudices and biases in themselves, and be willing to act when presented with inappropriate words or behaviors that are prejudiced or discriminatory. (Holly) 
Through their personal commitment to more inclusive libraries, the participants responded to the call to spread their new knowledge and awareness to others:

The course has not only broadened my thinking but has given me the confidence, as well as substantive information upon which I can draw to make my point. Furthermore, I am profoundly aware of the need for more people to advocate for what is just and equitable. Instead of diversity being this esoteric concept that I was unable to specifically define, I can now give it description, along with meaningful examples. I understand the value and importance of celebrating diversity and curating a collection that is inclusive to all (Hope).

\section{Discussion}

The education field has models for educating pre-service professionals offering specific, structured strategies that consider issues of diversity, equity, and inclusion (Gay, 2000; Ladson-Billings, 1995a). Similar critical consideration is necessary in the library setting. Through the identification of the themes in this study, beginning structure can be cast for LIS programs training pre-service librarians to engage with those they will serve.

This exploratory study examines how the use of a cultural competency framework impacts emerging librarians' perspectives on meeting racially diverse populations. The stages of the cultural competence framework were created to guide the development of the LIS course. The discussed findings suggest the framework, aligned to the principles of social justice, situated within coursework applying culturally relevant pedagogy information raised pre-service librarians' awareness level toward issues of racial diversity, equity, and inclusion. The coded findings document a shift toward empathy and a better understanding of those who are dissimilar to the participants. As participants progressed through the stages of the developed framework together, they grew in their ability to engage in courageous conversations (Singleton \& Linton, 2006) to push forward ideals of racial diversity and equity in a library setting: "Having these difficult or courageous conversations will help me to be less afraid to talk about racial issues with my peers and my patrons. It will help me to have these conversations in the most appropriate way" (Kim).

Engagement with the course materials allowed students to bridge knowledge of race and racial tensions and engage in difficult conversations that would otherwise be elusive as demonstrated by Holly, "Rankine's work spoke to me about what it is like to not be a part of the dominant white culture in America, to live in a black body in today's society and carry, without choice, that weight". Delgado and Stefanic (2012) argue that most people do not come into contact with many people of radically different race or social station. We tend to read materials written by and interact with people of our own culture. Individuals can, however, develop empathy for people who have other cultural experiences (2012, p. 33-34). Therefore, findings demonstrating a greater awareness and empathetic stance toward people of different races when approached 
through the course texts support this assumption. As demonstrated by Amy, who in initial reflections confronting her racial bias stated, "I don't want to be viewed negatively so I just avoid any of these discussions" showed considerable growth in empathy in a later discussion stating,

I find myself, already, asking more questions about my own assumptions, practices, and choices with an increased passion for asking these same questions of others. At the same time, I am driven to know more so that I can do better in my defense of those whose voices have been and are being marginalized.

Race is a deeply embedded social construct (Ladson-Billings, 1998, p. 8). To effectively increase a participant's awareness of how race plays a role in systemic interactions throughout many peoples' everyday lives, the course texts and readings proved valuable. This was sustained as participants shift their anticipated actions to plan to better meet the needs of a racially diverse set of patrons in their future information settings: I'm a little daunted and a whole lot inspired by the scope of the work that can be and is being done to not only ensure all patrons receive the information they need to grow, learn, think, and create in ways that are important and relevant to them but also in the deliberate efforts to ensure that every patron feels noticed, known, and respected by library staff and through the resources available at the library (Holly).

Though derived from an educational framework, the pedagogy framework is beneficial preparing for the library setting that is a service profession. The use of a cultural framework in a LIS preparation program to train preservice librarians to engage with those they will assist prepared participants to move past their initial reluctance to identify and own bias to a realization that racial awareness brings voice.

A library preparation program that does not critically interrogate race, power, diversity, class, and privilege in the context of meeting the needs of all patrons its graduates will serve runs the risk of disenfranchisement of those patrons. Participants left this course with an energy to refocus their perspective, "I am excited to begin helping myself and my community become more culturally aware" (Cat).

\section{Limitations}

This study is not without limitations. All results of the bias inventory assessments were self-reported. While many students chose to self-assess on racial bias, not all completed this bias inventory and some of those who did found themselves in a conflict of agreement with the results. In an effort to capture authentic student bias, race was not a required area for students to explore. This study focused only on the DEI perspectives of race and racial perceptions. Participants also discussed a variety of other under-represented or underserved populations in their reflections and these discussions are beyond the scope of this study. Finally, this study focused on the perspectives of one set of students in one course. Future studies may look at a 
broader sample or may alter the data samples used to explore student perceptions. Despite these limitations, this study makes a significant and needed contribution to the discussion of LIS preparation.

\section{Implication and Conclusions}

This study suggests that a course dedicated to diversity and equity, particularly when framed using a culturally responsive pedagogy framework that includes personal reflection, may have a positive impact on student awareness of their own cultural backgrounds in relation to student beliefs and perceptions of others. Change in discourse over the course demonstrated a shift in language from defensive to more empathic and open to diverse opinions and beliefs specifically explored through the principles of cultural teaching. The framework served to assist preservice librarians identify racial diversity for the purpose of determining anticipated needs of a diverse library population. Findings support this model may be beneficial in for LIS programs where training that considers a diverse set of library users and provides structured strategies for developing critical consciousness.

In conclusion, this exploratory action research study indicates that although diversity, equity and inclusion are tenets built on the core values of librarianship, these ideals must be explicitly taught in LIS coursework. Having a framework upon which to build this instruction is critical. Many emerging librarians want to believe that they hold DEI values. The optimal opportunity for shifts in understanding occur as students engage with course materials. Infusing discussions of race and social justice within a course using a culturally responsive pedagogy framework participants begin to examine their own beliefs about race and shift their understanding toward personal growth

\section{References}

Adams, M., Bell, L.A., \& Griffin, P. (2007). Teaching for Diversity and Social Justice. New York, NY: Routledge.

American Library Association [ALA]. (1996). Library Bill of Rights. Accessed from:

http://www.ala.org/advocacy/sites/ala.org.advocacy/files/content/LBORwithInterpretation s.pdf

American Library Association [ALA]. (2010). B.3 Diversity. Accessed from: http://www.ala.org/aboutala/governance/policymanual/updatedpolicymanual/section2/3di versity

American Library Association [ALA]. (2019). Core values of librarianship. Accessed from: $\mathrm{http} / / / \mathrm{www}$.ala.org/advocacy/intfreedom/corevalues

Charmaz, K. (2006). Constructing grounded theory. London, England: Sage.

Cochran-Smith, M. (2010). Toward a theory of teacher education for social justice. In A. Hargreaves (Eds.), Second international handbook of educational change, Dordrecht, The Netherlands: Springer. 445-467. 
Creswell, J. (2012) Educational research: Planning, conducting, and evaluating quantitative and qualitative research, 4 th $E d$. Pearson.

Darling-Hammond, L. (2010). Constructing 21st century teacher education. In V. Hill- Jackson \& C. W. Lewis (Eds.), Transforming teacher education: What went wrong with teacher training and how we can fix it. Sterling, VA: Stylus, 223-248.

Delgado, R. \& Stefancic, J. (2012). Critical race theory: An introduction, $2^{\text {nd }}$ Ed. New York, NY: University Press.

Desmond, M. (2016). Evicted: Poverty and profit in an American city. New York, NY: Penguin Random House.

DiAngelo, R. (2018). White fragility: Why it's so hard for white people to talk about race. Boston, MA: Beacon Press.

Drago-Severson, E. (2016). Teaching, learning, and leading in today's complex world. Reaching new heights with a developmental approach. International Journal of Leadership in Education, 19(1), 56-86.

Goodwin, A. L. (1997). Historical and contemporary perspectives on multicultural teacher education. In J. King, E. Hollins, \& W. Hayman (Eds.), Preparing teachers for cultural diversity (pp. 5-22). New York: Teachers College Press.

Hayes, D. \& Singh, A. (2012). Qualitative inquiry in clinical and educational settings. New York, NY: Guilford Press.

Kugler, J. \& West-Burns, N. (2015). The CUS framework for culturally responsive and relevant pedagogy. Centre for Urban Schooling. Accessed from: https://cus.oise.utoronto.ca/UserFiles/File/CUS\%20Framework.pdf

Ladson-Billings, G. (1995a). But that's just good teaching! The case for culturally relevant pedagogy. Theory Into Practice, 34(3), 159-165.

Ladson-Billings, G. (1995b). Toward a theory of culturally relevant pedagogy. American Education Research Journal, 32, 465-491.

Rankine, C. (2014). Citizen: An American lyric. Minneapolis, MN: Graywolf Press.

Singleton, G. \& Linton, G. (2006). Courageous conversations about race: A field guide for achieving equity in schools. Thousand Oaks, CA: Corwin.

United States Census Bureau [USCB]. (2018). Race. Accessed from: www.census.gov/topics/population/race/about.html 